\title{
EL URBANISMO EN CATALUÑ̃A: EVOLUCIÓN HISTÓRICA Y RETOS PARA EL FUTURO INMEDIATO
}

\author{
URBAN PLANNING IN CATALONIA: HISTORICAL \\ EVOLUTION AND IMMEDIATE FUTURE CHALLENGES
}

\begin{tabular}{|c|c|}
\hline \multicolumn{2}{|c|}{ ARTÍCULO INÉDITO DE INVESTIGACIÓN } \\
\hline CÓMO CITAR ESTE ARTÍCULO (CHICAGO) & $\begin{array}{l}\text { Trayter Jiménez, Joan Manuel. "El urba- } \\
\text { nismo en Cataluña: Evolución histórica } \\
\text { y retos para el futuro inmediato". Revista } \\
\text { de Derecho Aplicado LLM UC } 6 \text { (2020). } \\
\text { doi: Io.7764/rda.o.6. I6677. }\end{array}$ \\
\hline REVISTA DE DERECHO APLICADO LLM UC & $\begin{array}{l}\text { Número } 6 \\
\text { Diciembre } 2020 \\
\text { ISSN: } 245^{2-4344}\end{array}$ \\
\hline & $\begin{array}{l}\text { Recepción: I de julio, } 2020 \\
\text { Aceptación: } 27 \text { de julio, } 2020\end{array}$ \\
\hline
\end{tabular}




\section{Resumen}

La ordenación urbanística en Cataluña, basada en las competencias exclusivas que, sobre la materia, ostenta este territorio según la Constitución española, ha sido objeto de una importante evolución desde que -a finales del siglo XIX - Idelfons Cerdà construyera su teoría general de la urbanización. Así se abordan cuestiones clave, como la relación entre la ordenación de la ciudad, su inclusión en el territorio y la protección del medio ambiente, protección que en Europa se ha hecho mediante técnicas urbanísticas como la planificación. Una segunda cuestión es el análisis de las tendencias para ordenar la ciudad y sus nuevos barrios. Aquí la apuesta es por el multifuncionalismo, es decir, que cada nuevo barrio de la ciudad debe integrar diversos usos o funciones (residencias, negocios, escuelas, campos de deporte), en contraposición a las tesis monofuncionales, que dibujan una ciudad con las residencias en las afueras, grandes supermercados y en el centro oficinas. En tercer lugar, se abordan los problemas de la vivienda y los fenómenos de su carestía, su escasez y la inmigración. Por último, se analiza el alcance del control judicial.

Palabras clave: Urbanismo, medio ambiente, vivienda, inmigración, control judicial

\section{Abstract}

Urban planning in Catalonia, based on the exclusive powers that this territory holds according to the Spanish Constitution, has undergone an important evolution since - at the end of the 19th century - Ildefons Cerdà built his general theory of urbanization. This addresses key issues, such as the relationship between city planning, its inclusion in the territory, and the protection of the environment, protection that in Europe has been done through urban techniques such as planning. A second issue is the analysis of trains to order the city and its new neighborhoods. Here the bet is for multifunctionalism, that is, that each new neighborhood of the city must integrate different uses or functions (residences, businesses, schools, sports fields), in contrast to monofunctional theses, which draw a city with residences on the outskirts, large supermarkets, and offices in the center. Third, the problems of housing and the phenomena of shortages and immigration are addressed. Finally, the work analyzes the scope of judicial control.

Keywords: Urban planning, environment, housing, immigration, judicial control 


\section{Joan Manuel Trayter Jiménez}

Universidad de Girona

Girona, España

joan.trayter@udg.edu
Universidad de Girona

Girona, Spain

joan.trayter@udg.edu
Joan Manuel Trayter Jiménez es catedrático de Derecho Administrativo de la Universidad de Girona, España. Licenciado en Derecho por la Universidad de Barcelona, España, y doctor en Derecho por la misma universidad. Es autor de nueve monografías de derecho público, entre las que destacan El control del planeamiento urbanístico (1997), Derecho administrativo: Parte general (quinta edición de 2020) y Derecho urbanístico de Cataluña (octava edición de 2020). Ha sido miembro de la Comissió Jurídica Assessora de la Generalitat de Catalunya y vocal de la Junta Electoral Central. Actualmente es director del Centro de Innovación y Gestión de las Administraciones Públicas.

Joan Manuel Trayter Jiménez is a Professor of Administrative Law at the University of Girona, Spain. Degree in Law from the University of Barcelona, Spain, and Doctor of Law from the same University. $\mathrm{He}$ is the author of nine monographs on public law, among which are El control del planeamiento urbanístico (1997), Derecho administrativo: Parte general (5th edition, 2020) y Derecho urbanístico de Cataluña (8th edition, 2020). He has been a member of the Comissió Jurídica Assessora de la Generalitat de Catalunya and the Central Electoral Board. Nowadays, he is director of the Center for Innovation and Management of Public Administrations. 


\section{EL ORIGEN DEL DERECHO URBANÍSTICO: ILDEFONS CERDÀ}

Con el fin de diseñar una nueva forma de abordar la organización del espacio en las ciudades, un ingeniero catalán, Ildefons Cerdà (1815-1876) recurrió a un neologismo formado a partir del latín urbs para construir su "teoría general de la urbanización", que fue plasmada en 1867 y que constituye el primer tratado del mundo sobre la materia ${ }^{1}$. Rápidamente, se acuñó el término urbanismo que, a partir de esa obra, abordaría con sustantividad propia los problemas que la era industrial planteaba a la ciudad del antiguo régimen. Ese concepto pasa a la legislación francesa (urbanisme), a la italiana (l'urbanística) y permite que el verbo urbanizar - es decir, "ordenar la ciudad" - desplace a circunloquios que hasta entonces se habían empleado, en particular, "la construcción o edificación de la ciudad", para referirse a lo que hoy denominamos urbanismo.

A este genial personaje, al que el poder no se lo puso fácil y que tuvo que luchar contra los prejuicios de la sociedad de su época, no solo le debemos la configuración del ensanche de muchas grandes ciudades. También sienta los fundamentos para el establecimiento de los actuales instrumentos legales y conceptos como vialidad, zonas de uso público - es decir, las calles y las plazas-y de uso particular - esto es, manzanas y viviendas-, y pone los mimbres de lo que en la actualidad es la moderna ordenación del territorio: donde hemos de pasar nuestras vidas, la ciudad, "no puede estar separada del campo que ha de proporcionar los medios para mantenerla”.

Esta perspectiva integradora entre el hombre y el territorio donde desarrolla su vida, de la que Cerdà fue precursor, ha sido objeto de estudio desde la sociología, la arquitectura, la sanidad, la ecología, la economía y el derecho, todo lo cual debe coordinarse y articularse.

El urbanismo, en la actualidad, es un conjunto de reglas que, desde una visión global, regula los aspectos de la relación entre el hombre y el medio en el que se desenvuelve. Así, el derecho urbanístico constituye una importante parte del derecho administrativo, que comprende un compendio de normas a través de las que se regula la ordenación del territorio, la propia urbe (la ciudad) y la vivienda. En esa línea incluye un conjunto de reglas protectoras del medio ambiente que, a su vez, sirven para controlar y regular el proceso urbanizador: el denominado urbanismo ambiental.

El objetivo de este trabajo es exponer las tendencias actuales del derecho urbanístico en Europa, tomando como ejemplo el caso de Cataluña, comunidad autónoma que tiene competencias exclusivas en la materia.

1 Sobre Ildefons Cerdà y su obra resulta capital, Teoría de la construcción de las ciudades aplicada al proyecto de reforma del ensanche de Barcelona y Madrid (Barcelona: MAP, Ayuntamiento de Barcelona, r99I). 


\section{BREVES HITOS HISTÓRICOS}

Tras unas décadas de constitucionalismo en España, son las ordenanzas municipales sobre policía urbana y rural los cuerpos normativos las que, de forma caótica y fraǵmentada, regulan algunas cuestiones urbanísticas. Así, la Ordenanza de Barcelona del 11 de noviembre de 1856 sistematiza temas tan importantes como la necesidad de someter cualquier nuevo edificio que se proyecte al plan de alineaciones aprobado por la municipalidad, estableciendo previsiones sobre la instalación de calderas de vapor, así como regulando un conjunto de temas de policía urbana (riesgo de incendios, mercados, tiendas, transportes), normas que deberán observarse para la construcción de nuevos barrios o fuera del recinto de la ciudad. Con ello, si bien se superaba la concepción de la ciudad medieval, separada de su entorno por una muralla defensiva cuyas puertas se cerraban al caer el sol, no se llegaba a conseguir todavía un corpus jurídico urbanístico. Esta idea, tal como explica el profesor Martí Bassols Coma², se completaría con el levantamiento de los planos geométricos de las ciudades y la representación cartográfica de calles, plazas y perímetro de población, tanto presente como futura. El ensamble de estos dos instrumentos (ordenanzas y planos geométricos o cartográficos) dará lugar a lo que en la actualidad denominamos plan urbanístico, auténtico origen del urbanismo en Cataluña.

La legislación del ensanche, por su parte, con el fin de superar las centenarias murallas, constituirá la primera normativa urbanística tal y como se entiende en la actualidad. Así, ante el impresionante crecimiento demográfico - Barcelona, por ejemplo, duplicó en el siglo XIX su población y en los treinta primeros años del siglo XX alcanzó la cifra del millón de habitantes-, se dictó la Ley del 29 de junio de 1864 relativa al ensanche de poblaciones, a caballo de la que con que se aprueba el plan Cerdà, por Real Decreto del 7 de junio de 1859. Esta normativa incluye, para los nuevos barrios, la necesidad de dictar los proyectos de ensanche, en que se recogen las previsiones sobre obras de urbanización, expropiaciones, planes económicos, sistemas de gestión y alturas máximas de los edificios, además de la memoria que debía acompañar a cada proyecto de ordenanza de la construcción y policía urbana.

El desarrollo posterior de ese esqueleto no sufre modificaciones con las leyes del 26 de julio de 1892, de ensanche para Barcelona, y del 18 de marzo de 1895, sobre saneamiento y reforma interior de las grandes poblaciones que contemplaba la Ley de Expropiación Forzosa del 10 de enero de 1879. Esta ley recoge la primera técnica de configuración de plusvalías derivadas de la urbanización, al autorizar la expropiación de las zonas laterales de las nuevas vías públicas, así como estímulos fiscales.

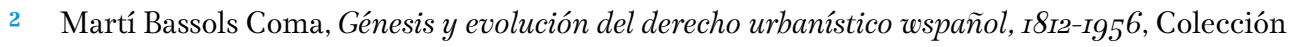
de Estudios Jurídicos, monografías núm. 40 (Madrid: Montecorvo, I973). 
En la ciudad de Girona, por su parte, y junto al inconmensurable Barri Vell, creció la ciudad de manera armoniosa, en que se derrumbaron los inmuebles, pero con una continuidad urbanística. El Pont de Pedra, la avinguda Sant Francesc, la plaça Sant Agustí o algunos tramos de la calle Santa Clara son sus ejemplos más relevantes. Con posterioridad, en 1909, fue aprobado el Pla de l'Eixample, ideado por el arquitecto Eugeni Campllonch, que tuvo sus claroscuros en la ejecución, lo que llevó a una cierta falta de cohesión que ha sido el caballo de batalla de finales del siglo XX: conseguir la solidaridad entre los diferentes barrios de Girona.

Mientras tanto, la legislación sanitaria de principios de siglo introdujo, en toda Cataluña, algunas novedades significativas. Tras otorgar a los ayuntamientos la potestad de aprobar reglamentos de higiene, la Real Orden del 9 de agosto de 1923 puso en marcha las condiciones higiénicas de las viviendas y las condiciones técnico-sanitarias para el ensanche y reforma interior de las poblaciones. Esta norma introdujo en nuestro derecho como novedad - pese a su limitado alcance - la técnica de la zonificación y la fijación de los estándares urbanísticos sanitarios, que pasarán luego, literalmente, al Reglamento de Obras, Servicios y Bienes Municipales del 14 de julio de 1924.

La citada legislación generaliza la obligación de formular proyectos de ensanche en los pueblos mayores de 10.000 almas que en el período de 1910 a 1920 hubieran experimentado un aumento de población superior al 20\%. Al redactar esos proyectos - que hoy denominaríamos planes de ensanche-, se debían observar los preceptos técnico-sanitarios incluidos por cada ayuntamiento en sus ordenanzas o, en su defecto, los principios recogidos en la declaración de utilidad pública de las obras proyectadas y la necesidad de ocupación de los terrenos y edificios afectados por el trazado de las calles.

En definitiva, se superó la perspectiva técnico-sanitaria de los planes estableciéndose una ordenación integral del territorio contemplando, junto a los proyectos de ensanche, los proyectos de reforma interior y los planes generales de alineaciones, todo ello con constantes llamadas a la regulación legal mediante ordenanzas municipales. El Reglamento de Obras, Servicios y Bienes Municipales, del 14 de julio de 1924, al que nos hemos referido, sistematizó toda la normativa existente hasta entonces y consolidó técnicas como la superficie máxima edificable, los índices mínimos de zona verde por habitante, reglas de anchura de las calles, etcétera.

Con la Segunda República se recogieron las nuevas concepciones del planeamiento urbanístico como una ordenación racional, abstracta e integral del territorio, superando la concepción técnico-sanitaria. Sin embargo, esas ideas no llegaron a plasmarse en ninguna legislación concreta, pues todos los proyectos fueron frustrados por la Guerra Civil. Únicamente se ha destacar que la Generalitat acordó, el 3 de octubre de 1931, la formulación de un anteproyecto de "Pla de distribució de zones del territori català", encargado a los arquitectos y hermanos Rubió-Tudurí, y que, publicado en 1933, constituyó el primer plan regional de Europa. 
Tras la Guerra Civil, la Ley de Bases de Régimen Local, del 17 de julio de 1945, dio un paso más en la concepción de nuestro actual derecho urbanístico como un conjunto de normas de derecho público y previó el denominado Plan General de Urbanización, como plan conjunto de la ciudad que tuvo su reflejo en el Plan General de Barcelona de 1953. En él, aun sin llegar a ser un instrumento de ordenación integral del territorio, por cuanto se refería únicamente al núcleo habitado ("la aglomeración humana"), se constituyó una coordinación de los planes de reforma interior y ensanche, con la finalidad de reconstruir las zonas destruidas por la Guerra Civil.

La necesidad de dictar una ley para cada plan no podía perpetuarse y, por ello, se dictó la Ley del Suelo y Ordenación Urbana, del 12 de mayo de 1956. En nuestro sistema de derecho público es esta ley la que certifica el acta de nacimiento del derecho urbanístico, incorporando las grandes ideas que aún hoy presiden la regulación: la responsabilidad de las Administraciones Públicas en la ordenación urbanística del territorio, tanto en la planificación como en el régimen jurídico del suelo; la gestión urbanística; las reglas de intervención y uso del suelo; y un nuevo estatuto del derecho de la propiedad, no basado en la concepción romana del derecho a gozar de los bienes sin más limitaciones que las previstas en las leyes, para convertirse en un derecho limitado en su contenido, que viene determinado en cada caso concreto por las leyes urbanísticas y los planes.

No obstante, esta ley, fruto del trabajo del profesor Manuel Ballbé, topó con su fracaso aplicatorio, con una Administración autoritaria, lenta, opaca y con poca capacidad de gestión, que, en veinte años, solo fue capaz de aprobar 600 planes generales, lo que llevó a la disociación entre norma y realidad: law in book, law in action, en clásica referencia anglosajona. No podemos olvidar que la idea de remitir al plan la ordenación de la ciudad y no a la ley aprobada por el Parlamento continúa siendo la base del sistema, pues permite, respetando la jerarquía de normas, regular y ordenar cada territorio de manera más adecuada a sus características físicas y su entorno.

En 1972 se inició, con la publicación del documento "El porqué de una reforma”, la justificación de lo que sería la Ley del 2 de mayo de 1975. Su objetivo, dice Tomás Ramón Fernández $z^{3}$, era, manteniendo el esqueleto de la Ley del 1956, flexibilizar la aprobación de los planes y establecer unos criterios materiales de planeamiento para forjar, de esta manera, los denominados estándares urbanísticos o índices numéricos mínimos que han de respetar todos los planes - tanto por ciento de zonas verdes, aparcamientos, etcétera-, para asegurar así unos objetivos de calidad de toda nueva construcción y edificación. Asimismo, profundizó las cesiones obligatorias y gratuitas llamadas a garantizar una participación mayor de la sociedad en las plusvalías generadas por la urbanización, mejoró

3 Tomás Ramón Fernández, Manual de derecho urbanístico, 26. ${ }^{\text {a }}$ ed. (Madrid: Thomson Reuters, 20I9). 
las técnicas de obtención de beneficios y cargas en la ejecución del plan y reforzó los mecanismos preventivos y sancionadores para lograr una mejor disciplina urbanística.

El problema de esta norma fue que su entrada en vigor coincidió con el inicio de la crisis económica y, para entonces, la perspectiva de ensanche y producción de suelo urbano no casaba con la nueva realidad, pero fue la que mantuvo el texto refundido de la Ley de Régimen del Suelo y Ordenación Urbana del 9 de abril de 1976, aprobado por el Real Decreto 1346/76, del 9 de abril, resultado de la reforma y de la refundición de las dos normas (la Ley de 1956 y la de 1975). Esta ley, técnicamente buena, chocó con dos problemas añadidos: por un lado, la carencia de instrumentos ágiles para operar en suelo urbano; por otro, un incorrecto control en la aplicación tanto por las Administraciones Públicas como por la jurisdicción contencioso-administrativa que, en demasiadas ocasiones, denegó la suspensión de planes urbanísticos o de los actos aplicativos de éstos - cuando eran claramente ilegales-y que todavía en menos ocasiones ejecutó las sentencias que ordenaban la demolición de lo construido de manera ilegal, a pesar de que, desde el 27 de diciembre de 1956, la Ley de la Jurisdicción Contenciosa-Administrativa encargaba a los jueces de lo contencioso la labor de control del urbanismo en Cataluña.

\section{LAS PRINCIPALES CUESTIONES TRAS LA CONSTITUCIÓN DE 1978}

\section{I. La estructura del derecho urbanístico}

Es lógico que la aprobación de la Constitución hoy vigente, el 6 de diciembre de 1978, produjera a corto o medio plazo importantes cambios en el derecho urbanístico catalán en dos aspectos: material y competencial².

4 Analizando la cuestión competencial: Eduardo García de Enterría y Luciano Parejo Alfonso, Lecciones de derecho urbanístico (Madrid: Civitas, I979); Fernández, Manual...; Jesús González Pérez, Comentarios a la Ley del Suelo (Madrid: Civitas, I988); Antonio Carceller Fernández, Introducción al derecho urbanístico (Madrid: Tecnos, 1992); Francisco Lliset Borrell, José A. López Pellicer y Federico Romero Hernández, La Ley del Suelo: Comentarios al texto refundido de $199^{2}$ (Madrid: El Consultor, 1993); Tomás Quintana López (coordinador), Derecho urbanístico estatal y autonómico (Valencia: Tirant lo Blanch, 200I); José Bermejo Vera, Derecho administrativo: Parte especial (Navarra: Thomson-Civitas, I999); Fernando López Ramón, Introducción al derecho urbanístico (Madrid: Marcial Pons, 20I3). En particular y de inexcusable referencia, ha visto la luz el libro de José María Baño León, Derecho urbanístico común (Madrid: Iustel, 2009).

De la Ley de Suelo, destaca la obra de Luciano Parejo Alfonso y Gerardo Roger Fernández, Comentarios a la Ley de Suelo (Decreto legislativo 2/2008, de 20 de junio) (Madrid: Iustel, 2008).

También resultan destacables los tres tomos del libro homenaje al profesor Martí Bassols Coma. Sobre el sistema de distribución de competencias, véase Ángel Menéndez Reixach, "Las competencias del Estado y de las comunidades autónomas sobre el régimen del suelo: Comentario crítico a la STC de 20 de marzo

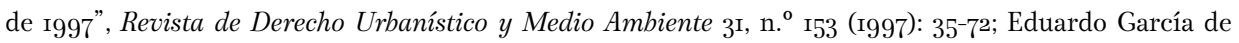
Enterría, "Una reflexión sobre la supletoriedad del derecho urbanístico español a la vista del siglo XXI", Revista Española de Derecho Administrativo 95 (1997): ${ }_{4}^{07-214}$; Javier Barnes Vázquez, "La distribución de competencias entre el Estado y las comunidades autónomas en materia de urbanismo: Una síntesis de los

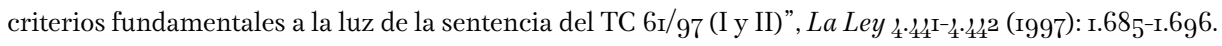


Desde el punto de vista del contenido del derecho urbanístico, varios preceptos han puesto la semilla que ha ido extrayendo y cultivando la doctrina, el legislador y los propios tribunales de justicia.

Así, en el artículo 33 de la Carta Magna se reconoce el derecho a la propiedad privada en el marco de la función social que esta cumple. Dicho precepto, además de impedir la acumulación pura y simple de la propiedad o su confiscación - sin pago alguno a cambio-, asegura el retorno a la comunidad de los aumentos de valor que ella misma genera por el proceso urbanizador. Esa es su mayor virtualidad: la de proporcionar, con la técnica que en cada caso las leyes urbanísticas dibujen, el retorno de las plusvalías a la comunidad que se genera con el proceso urbanizador. Por ello, el apartado segundo del precepto señala que la función social de derecho de propiedad delimitará su contenido, de acuerdo con las leyes. La ley, salvado su contenido esencial (artículo 53.1 de la Constitución), debe concretar las facultades que lo componen (así, el artículo 4.1, texto refundido de la Ley de Suelo y Rehabilitación Urbana 7/2015, del 30 de octubre, que es ley vigente en España en materia urbanística).

Así mismo, el artículo 47 de la Constitución obliga a los poderes públicos a regular la utilización del suelo de acuerdo con el interés general con el fin de evitar la especulación. Estos preceptos, dice Fernández, dibujan un límite mínimo - la participación de las plusvalías generadas por las decisiones de estos-y otro máximo - el obligado respeto al contenido esencial del derecho de propiedad- ${ }^{5}$. Además, ese artículo 47 impone hacer efectivo el derecho a disfrutar de una vivienda digna y adecuada, una vivienda como hábitat, como residencia habitual; de ahí las leyes del derecho a la vivienda (Ley Catalana 24/91, del 24 de diciembre, substituida por la Ley 18/2007, del 28 de diciembre, del Derecho a la Vivienda). Este precepto constitucional, junto con los artículos 45 y 46 , contemplan la denominada constitución ambiental y el derecho urbanístico ambiental, frente al urbanismo desarrollista volcado en la creación de la ciudad.

En la misma línea, se exige un deber de conservar el patrimonio histórico heredado, sobre todo en la ciudad, donde se encuentran los bienes culturales que constituyen un patrimonio colectivo. Esta línea, cuya idea acabada se encuentra en la sentencia del Tribunal Constitucional 102/1995, del 26 de junio y en la sentencia 119/2001, del 24 de mayo, concibe el medio ambiente urbano en permanente interacción con el rural. A ello nos referiremos con posterioridad, ya que es, desde 2002, la apuesta del derecho urbanístico catalán.

$5 \quad$ Fernández, Manual... 


\subsection{Las competencias en Cataluña}

El urbanismo, tradicionalmente, ha sido una competencia municipal. Al Estado se le atribuían las facultades de tutela municipal (la aprobación definitiva de los planes y las potestades en materia de subrogación en la disciplina urbanística). Ese esquema venía completado por las políticas sectoriales en diversos ámbitos (usos públicos, información y turismo, patrimonio histórico) y por la corporación metropolitana de Barcelona, que servía a la idea de planificar en conjunto los distintos municipios del denominado "cinturón rojo" de Barcelona.

De ese modo, la Generalitat empezó a ejercer las competencias en materia de urbanismo el 1 de octubre de 1978, con el Real Decreto 1385/1978, del 23 de junio, de traspaso de las competencias de la Administración del Estado, en el marco de una legislación urbanística preconstitucional constituida por el texto refundido de 1976 y por los reglamentos de desarrollo.

El Estatuto de Autonomía de 1979, en concreto el artículo 9.9, de conformidad con lo dispuesto por el artículo 148 de la Constitución, otorgó a la Generalitat competencia exclusiva en materia de urbanismo, más en específico, sobre la ordenación del territorio y del litoral, urbanismo y vivienda.

En desarrollo de este marco competencial se han ido aprobando un conjunto de leyes con la finalidad de configurar un ordenamiento jurídico urbanístico propio de Cataluña. En principio, en el marco de la citada legislación preconstitucional, se aprobaron la Ley 4/1980, del 16 de diciembre, de Creación del Institut Català del Sòl, y la Ley 9/1981, del 18 de noviembre, sobre Protección de la Legalidad Urbanística, esta última con la finalidad de poder disponer de los instrumentos necesarios para velar por la prevalencia del orden jurídico urbanístico, sin menospreciar la seguridad jurídica de los administrados y, en particular, para afrontar la gravísima problemática derivada del fenómeno de las urbanizaciones ilegales. Luego, se aprobó la Ley 3/1984, del 9 de enero, de Medidas de Adecuación del Ordenamiento Urbanístico de Cataluña, que tenía por objeto la adaptación del ordenamiento urbanístico a las particularidades de Cataluña, en cumplimento de la que se elaboró el impropiamente denominado código urbanístico catalán.

Este marco normativo se mantuvo hasta 1990, cuando se aprobó el Decreto Legislativo 1/1990, del 12 de julio, de refundición de los textos legales vigentes en Cataluña en materia urbanística.

La aplicación de esta Ley en Cataluña evitó la vigencia de la Ley Estatal (básica) 8/1990, del 25 de julio, de Reforma del Régimen urbanístico y valoraciones del suelo, que establecía un extraño proceso de adquisición gradual de derecho de propiedad y que culminaba, después de múltiples obstáculos, con la del derecho a la edificación. Esta última ley fue 
impugnada ante el Tribunal Constitucional, impugnación a la que después se añadió el Decreto Legislativo 1/1992, del 26 de junio, que refundía los aspectos vigentes la Ley de 1976 y que fue declarada inconstitucional por la sentencia 61/1997, del 20 de marzo, que, por razones estrictamente competenciales, anuló más de doscientos artículos (ahora derogada).

La doctrina de esa sentencia, unida a la sentencia 164/2001, del 11 de julio, configura la competencia exclusiva de la Generalitat en materia urbanística y, por ende, la legislación urbanística en Cataluña.

De ese modo, y en síntesis, la doctrina constitucional es sencilla:

La Carta Magna no reserva al legislador estatal competencia alguna en materia de ordenación del territorio y urbanismo, por lo que ni siquiera puede promulgar normas con carácter supletorio. Le queda, por tanto, regular los aspectos que afectan a las condiciones básicas que garantizan el ejercicio de los derechos y deberes y, en concreto, el derecho de propiedad, es decir, el estatuto jurídico de la propiedad del suelo (artículo 149.1.1 de la Constitución). En esta línea, debe regular la responsabilidad patrimonial de la Administración Pública, las garantías generales de la expropiación forzosa y el régimen de valoración (artículo 149.1.18). Asimismo, le corresponde la legislación básica sobre protección del medio ambiente (artículo 149.1.23) y algunas otras cuestiones, como la que deriva de la competencia sobre las bases y coordinación de la planificación general de la actividad económica (artículo 149.1.13).

Al Estado le corresponde, además, la competencia en materia de aguas, costas - parcialmente-, puertos y marina mercante. Asimismo, es necesario recordar la doctrina del "interés general" o actuación que afecta a más de una comunidad autónoma, doctrina que sirve, según la jurisprudencia constitucional, para atribuir al Estado la competencia en determinadas materias - así, por ejemplo, obras públicas de interés general o que afectan a más de una comunidad autónoma (artículo 149.1.24) -, cuando sobre un mismo espacio físico deba hacerse una actuación sobre la que confluyan competencias de diferentes administraciones públicas.

Por el contrario, queda vedado al legislador estatal la imposición de un concreto modelo urbanístico a las comunidades autónomas, la imposición de técnicas urbanísticas, incluso las facultades urbanísticas de los propietarios, temas todos ellos que deben ser regulados por la comunidad autónoma a través de sus normas (sentencia del Tribunal Constitucional 164/2001, del 11 de junio, fundamento jurídico 32).

A partir de todo lo anterior, fue aprobada la Ley Estatal 6/1998, del 20 de julio, de Valoraciones del Suelo. Este esquema sirvió para la aprobación de la Ley 2/2002, del 26 de mayo, de Urbanismo de Cataluña, dictada durante la última parte de la legislatura en la que Convergència i Unió (CIU) ocupó el Gobierno, ley innovadora que inicia el camino del urbanismo ambiental y de cohesión social en Cataluña. 
Esta ley fue perfilada por la Ley 10/2004, del 24 de diciembre, de modificación de la Ley 2/2002, del 14 de marzo, para el fomento de vivienda asequible, de la sostenibilidad territorial y de la autonomía local. Luego, ambas normas fueron refundidas por el Decreto Legislativo 1/2005, del 26 de julio, por el que se aprueba el texto refundido de la Ley de Urbanismo de Cataluña, y desarrollada por el reglamento aprobado por Decreto 305/2006, del 18 de julio, este último aún vigente.

\section{LOS RETOS DEL DERECHO URBANÍSTICO: URBANISMO SOCIAL, URBANISMO AMBIENTAL}

\section{I. Las leyes vigentes}

El Estatuto de Autonomía de Cataluña, aprobado por Ley Orgánica de 2006, establece, como competencia exclusiva de la Generalitat de Cataluña, la ordenación del territorio, del paisaje del litoral y el urbanismo (artículo 149.5). Estatuto de Autonomía cuya interpretación por la sentencia del Tribunal Constitucional 31/2010 no ha afectado a la esencia de la competencia autonómica en la materia que abordamos.

El reconocimiento de esta competencia no impide, como ya hemos visto, la existencia de legislación estatal básica respecto de determinadas cuestiones que afectan al urbanismo. Esta legislación, en la actualidad, se encuentra recogida en el Real Decreto Legislativo 7/2015, del 30 de octubre, por el que se aprueba el texto refundido de la Ley de Suelo y Rehabilitación Urbanas. Esta ley, con la finalidad de evitar la dispersión normativa y el fraccionamiento de la legislación estatal, supuso refundir en un solo texto las siguientes normas: el Decreto Legislativo 2/2008, del 20 de junio, por el que se aprueba el texto refundido de la Ley de Suelo, y la Ley 8/2013, del 26 de junio, de rehabilitación, regeneración y renovación urbanas, conocida como la "ley de las tres erres".

Estas disposiciones deben ser tenidas en cuenta por la legislación catalana, actualmente recogida en el Decreto Legislativo 1/2010, del 3 de agosto, por el que se aprueba el texto refundido de la Ley de Urbanismo de Cataluña, ley que ha sido objeto de diversas modificaciones ${ }^{6}$.

6 Sobre esta Ley, véase Joan Manuel Trayter, Derecho urbanístico de Cataluña, 8. ${ }^{a}$ ed. (Barcelona: Atelier, 2010). Sobre las normas que la han precedido: Joan Manuel Trayter (director), Comentarios a la Ley de urbanismo de Cataluña (Pamplona: Thomson-Aranzadi, 2008); Francisco Lliset Borrell, Comentaris a la Llei d’urbanisme de Catalunya (Barcelona: Bayer Hermanos, 2004) y la de Carles Pareja Lozano, El nou Dret urbanístic (Madrid: Marcial Pons, i998); Enrique Sánchez Goyanes (director), Derecho urbanístico de Cataluña (Madrid: La Ley, 2009). Asimismo, Judith Gifreu i Font, L'ordenación urbanística a Catalunya (Madrid: Marcial Pons, Barcelona: ACM, 20I2); Joan Manuel Trayter y Carles García Rocasalva (directores), El desenvolupament de l'autogovern en materia de territorio, paisatge i urbanisme (Barcelona: IEA, 20I7). 
La legislación urbanística de Cataluña ha intentado abordar una serie de cuestiones, como la inmigración, la vivienda y el cambio del modelo de uso del suelo. Veamos en forma genérica las grandes líneas de su filosofía: el urbanismo social y el urbanismo ambiental.

\subsection{La preocupación social en las ciudades: Las normas del derecho a la vivienda}

Un conjunto de estudios tanto a nivel europeo como en el ámbito catalán han detectado cuáles son los nuevos problemas de las ciudades, que tanto el legislador como las administraciones públicas encargadas de planificar y aplicar la norma han de afrontar, lo que da un carácter marcadamente social a esta función pública que es el urbanismo.

Diferentes circunstancias han provocado, en Cataluña y el resto de Europa, una serie de fenómenos que pueden comprometer tanto la cohesión social como el desarrollo sostenible en el uso del territorio ${ }^{7}$. Estas circunstancias se pueden sintetizar en tres:

- El elevado precio de la vivienda, que ya ha alcanzado en algunas ciudades los mismos niveles previos a la crisis inmobiliaria de 2007.

- El lento cambio en el modelo de uso del suelo y los fenómenos derivados del denominado problema de "la mancha de aceite", es decir, de la urbanización progresiva y desordenada del territorio.

- El fenómeno de la inmigración.

Algunos datos sobre las cuestiones señaladas, obtenidos a partir de las informaciones publicadas por el Instituto de Estadística oficial de Cataluña (IDESCAT), la Asociación de Promotores de Cataluña (APCE) y el Observatorio Metropolitano de la Vivienda con su informe de 2017, "La vivienda en la metrópoli de Barcelona", resultan sumamente reveladores.

En cuanto al precio de la vivienda en Cataluña, durante los años posteriores a la crisis financiera internacional del año 2007, se produjo un descenso de las transacciones de compraventa y la contracción significativa de los precios. Sin embargo, después de este periodo, y en especial en los últimos tres años, se ha producido un aumento del precio de la vivienda tanto en el mercado de compra de obra nueva como de segunda mano. Así, respecto de las viviendas de obra nueva, durante el primer trimestre de 2019 se ha producido una subida interanual del 10,4\%, el ritmo más alto desde el 2007 antes de que estallase la crisis inmobiliaria, según el índice del precio de la vivienda (IPV) publicado

7 Joan Manuel Trayter, "Problemas actuales del derecho urbanístico en el mundo global: El ejemplo de Cataluña”, en Estudios de derecho público en homenaje a Luciano Parejo, vol. 3 (Valencia: Tirant lo Blanch, 20I8), 3.031-3.058. 
por el Instituto Nacional de Estadística (INE). Las causas de esta subida se atribuyen a la fuerte demanda de compra, junto con la escasez de nuevas promociones y el aumento de los costes de construcción. Respecto de la vivienda de segundo mano, su encarecimiento ha sido de 6,2\% respecto del año anterior, la tasa de crecimiento más baja desde mediados de 2017.

A la hora de analizar estos datos, no obstante, debe tenerse en cuenta que, de acuerdo con los informes emitidos por el Banco de España, el aumento de los precios no es uniforme por regiones ni por ciudades, sino que se concentra en las grandes capitales, como es el caso de Barcelona, y en algunas zonas costeras.

Por su parte, el mercado de alquiler también ha reflejado una importante evolución en los últimos años. Así, de acuerdo con los datos de las fianzas depositadas en el Institut Català del Sòl (INCASOL), en Cataluña, en el año 2018 hubo 7\% más de volumen de contratos de alquiler que en el año 2017, con un aumento de la renta media del 5,8\%.

En este contexto, en la ciudad de Barcelona, los gastos destinados al pago de la vivienda en el año 2016 representan de media $24,2 \%$ de las rentas de una familia, con los consiguientes problemas que ello conlleva para el acceso a la vivienda.

Respecto de la migración, en el año 2000 en la ciudad de Barcelona había empadronadas 74.772 nacidas en el extranjero (5\% de la población) y en el año 2009 se llegó a 335.652 (el 20,7\% de la población).

Coincidiendo con la crisis económica, la población extranjera se ha mantenido relativamente estable y, en el año 2016, se contabilizan 361.590 (22,5\% de la población). No obstante, estos porcentajes medios ocultan muchas diferencias entre los distintos distritos, pues en distritos como Ciutat Vella, la población nacida en el extranjero en el año 2016 representa el 50,7\% del total.

Estas dos circunstancias - problemas de la vivienda e inmigración - provocaron un constante avance del territorio urbanizado que se extiende como una "mancha de aceite" desordenada, a veces caótica, desintegrada, que lleva a una progresiva desestructuración de la ciudad, en la que están apareciendo nuevos suburbios o guetos urbanos, fenómeno que se ha frenado no gracias a la leyes urbanísticas, sino a la crisis inmobiliaria.

No obstante, todo ello se ha de poder evitar mediante las técnicas urbanísticas que seguidamente iremos apuntando. Antes, queremos hacer un breve repaso del entorno europeo para constatar que no vamos errados, desencaminados con los planteamientos de los problemas citados. Después daremos algunas ideas sobre la aplicación de ciertas técnicas urbanísticas que lleva a cabo, a modo de filosofía general, la legislación catalana. 
En primer lugar y en el ámbito de la Unión Europea, ya desde la década de los noventa se han aprobado una serie de documentos que forman parte del soft low, del derecho débil, pero que indican cuáles son las líneas de solución de problemas comunes. Desde el Libro verde sobre el medio ambiente urbano, elaborado por la Comisión, pasando por la nueva Carta de Atenas del Consejo Europeo de Urbanistas o el Programa Agenda 21 de la Conferencia de Naciones Unidas sobre medio ambiente y desarrollo de la Declaración de Río de Janeiro, se quiere superar el enfoque sectorial en el trato de problemas de la ciudad, dando entrada a las opciones sociales y económicas que se encuentran en la base de estos. Recogiendo la tradición medieval, las ciudades se identifican con la cohesión social, las oportunidades de progreso, la capacidad de elección y la participación en los asuntos públicos. Ante esto, se constata el avance constante de la urbanización que, en la época contemporánea, determina el surgimiento de guetos urbanos. En consecuencia, se propone el establecimiento de un compromiso con las auténticas y originales esencias urbanas. Como alternativa al crecimiento suburbano indiferenciado, que segrega al individuo, se busca restablecer "la ciudad diversa y multifuncional de la Europa de los ciudadanos".

En tal contexto, no resultan sorprendentes las críticas hacia el monofuncionalismo urbanístico y sus modernas concreciones, como la construcción de grandes centros comerciales y de oficinas de la periferia o la especialización del centro, que tiende a ser convertido, a través de la peatonalización, en una gran superficie de comercio elegante, servicios financieros y equipamientos turísticos. Se trata de crear ciudades que proporcionen un entorno atractivo para sus habitantes, mediante la técnica de la planificación urbanística y de la mezcla de usos.

Como veremos, la potenciación de una planificación ordenada y coordinada da como resultado unos planteamientos multiculturales, plurifuncionales y conservacionistas respecto de la depredación del territorio.

Si concretamos un poco más, a nivel de los ordenamientos de nuestro entorno, citaríamos como ejemplo el urbanismo francés. Las Lois de la solidarité et renouvelement urbains y L'Urbanisme et Habitat, del 2 de julio de 2003, nos dan una pista de las medidas a adoptar en nuestro país, dado que para luchar contra la denominada maladie du banlieu o enfermedad de los suburbios o guetos urbanos, se han tomado tres tipos de medidas: i) se establecen unos principios generales del derecho que necesariamente han de contemplar los planes y que son susceptibles de control judicial, obligando a prever una diversidad de usos urbanísticos en todas las zonas planificadas, principio trascendental para conseguir la integración social y evitar la disgregación; ii) se establecen las grandes directivas en materia de cohesión social en los planes supramunicipales, en concreto los shema de coherence territorial; iii) se recogen los denominados programas locales del hábitat,

8 López Ramón, Introducción.... 
en que se fijan las necesidades de la vivienda, así como las previsiones para conseguir el 20\% de viviendas de protección oficial entre los municipios que reúnan unas determinadas características.

¿Qué se ha hecho en nuestro ordenamiento? En Cataluña, tanto el texto refundido de la Ley de Urbanismo de Cataluña como su reglamento de desarrollo, según veremos, intentan incorporar las ideas europeas referidas. Empiezan diciendo que la articulación del territorio catalán como una realidad ambientalmente sostenible, funcionalmente eficiente, económicamente competitiva y socialmente cohesionada ha de ser el principal objetivo de la acción de los poderes públicos y de la normativa en materia de urbanismo y de ordenación del territorio. Para avanzar hacia estos fines, imprescindibles a la hora de garantizar el bienestar de las generaciones presentes y futuras, es necesario promover un modelo de urbanización que se caracterice, en términos generales, por la compacidad de los asentamientos, la diversidad de sus funciones y el carácter socialmente integrado de su población.

Los mecanismos para conseguir estos objetivos son: i) la elaboración de planes directores urbanísticos o planes territoriales, para la programación de políticas supramunicipales del suelo y la vivienda, que se incorporen a los planes municipales con la finalidad de conseguir la cohesión social; ii) el establecimiento de una reserva de viviendas de protección pública para el uso residencial de nueva implantación, tanto en el suelo urbano como en el suelo urbanizable (artículo 57.3 del texto refundido de la Ley de Urbanismo) evitando su concentración y previendo plazos para el inicio y finalización de estas construcciones; asimismo, se crean con esa finalidad las denominadas áreas residenciales estratégicas; iii) con la finalidad de garantizar la sostenibilidad territorial y, por tanto, la mejora de la gestión del suelo no urbanizable, la protección del paisaje y el uso racional del territorio, se establecen una serie de medidas objetivas, de obligatorio cumplimiento por parte de las administraciones públicas y exigibles por los ciudadanos ante los tribunales: la prohibición de edificar en terrenos de pendiente superior al 20\%, prohibición de reclasificar el suelo como consecuencia de un incendio forestal y la necesaria exclusión del proceso urbanizador de los terrenos que, por razones paisajísticas, arqueológicas, históricas o de otro tipo, se hayan de preservar como suelo no urbanizable; iv) el marco legal se completa con la Ley 18/2007, del 28 de diciembre, del Derecho a la Vivienda.

Para conseguir todo esto, que constituye un conjunto de normas imperativas que vinculan al planificador y que, por lo tanto, como decimos, son susceptibles de control jurisdiccional, el legislador da gran importancia a un nuevo documento de los planes, denominado memoria social, memoria vinculante para el planificador tal y como ya sucedió desde la célebre sentencia de la Plaza de la memoria vinculante del Tribunal Supremo (16 de junio de 1977) respecto de la tradicional memoria que, a modo de justificación del plan, debe incluirse como un documento de inexcusable observancia en los distintos instrumentos de ordenación urbanística. 
En materia de vivienda, las novedades normativas han afectado no solo a la Ley de Vivienda catalana, sino también al derecho urbanístico y al texto refundido de la Ley de Urbanismo.

A partir de 2018, la tendencia del legislador catalán en materia de vivienda ha pasado por intentar mejorar el acceso, debido a la necesidad que tienen las administraciones públicas catalanas de ampliar el parque público de viviendas. Esta necesidad surge debido al bajo nivel de promoción de vivienda protegida en contraposición a su elevada demanda. Como se indica en el preámbulo del Decreto Ley 17/2019, del 23 de diciembre, de medidas urgentes para mejorar el acceso a la vivienda, durante el mes de setiembre de 2019 las personas inscritas en el Registro de Solicitantes de Vivienda de Protección Oficial de Cataluña han sobrepasado las 189.000.

Por un lado, las nuevas medidas en materia de vivienda han sido introducidas por este Decreto Ley 17/2019, que ha supuesto un punto de inflexión no solo en esta materia, sino también en el derecho urbanístico.

En primer lugar, ha introducido modificaciones en la Ley 18/2007. Entre estas modificaciones destaca el nuevo concepto de vivienda vacía (modificado posteriormente por el Decreto Ley 1/2020, del 21 de enero), el nuevo modelo de vivienda de protección oficial y la moderación de los precios de alquiler de las viviendas libres.

Respecto de las viviendas vacías, según el último censo de la Unidad de Disciplina de Vivienda del Ayuntamiento de Barcelona, en marzo de 2019, en este municipio hay 10.052 viviendas vacías. A nivel autonómico, los últimos datos que se conocen son del año 2011, cuando el IDESCAT enumeró las viviendas vacías en un total de 448.356.

Otro de los cambios introducidos en la Ley 18/2007 es la instauración de un nuevo modelo de vivienda de protección oficial que permite calificar este tipo de viviendas como genéricas cuando el acceso a la vivienda de las personas usuarias pueda estar en régimen de propiedad, de arrendamiento u otro régimen de cesión del uso sin transmisión de la propiedad; o específicas, cuando el acceso a la vivienda de las personas usuarias esté solo en régimen de arrendamiento.

Pero los cambios introducidos en la Ley 18/2007 no se producen solo para las viviendas públicas, sino que también se introducen modificaciones para los alquileres de viviendas libres y, en concreto, para moderar sus precios. Según los últimos datos del IDESCAT de julio de 2019, la renta media en el alquiler de viviendas de Cataluña en el año 2018 era de $€ 698,36$. Entre los municipios con la renta de alquiler más elevada se encuentra Sant Cugat del Vallès, con $€ 1.149,55$ de media, y el municipio de Barcelona, donde esta cifra asciende hasta los $€ 929,57$. Este índice se calcula a partir de una serie de variables concretas de cada propiedad, entre ellas, la dirección del inmueble, la altura de planta que 
ocupa, los metros cuadrados, el año de construcción, su estado, el certificado energético y si dispone de ascensor, plaza de garaje y muebles. Puede consultarse a través del sitio web de la Agencia de Vivienda de Cataluña. Respecto de este punto, la norma obliga a indicar el índice de referencia en el anuncio de alquiler - y posteriormente en el contrato- para no superar el índice en 10\% o 15\% cuando el inmueble se sitúa en una "zona tensa" (pueblos o ciudades con mayores problemas de acceso al alquiler) y el $20 \%$ cuando se trate de viviendas de nueva construcción o con una reforma integral.

En segundo lugar, otro paquete de medidas que introduce este Decreto Ley y que aquí interesa es el relativo a las modificaciones de la Ley 24/2015, del 29 de julio, de medidas urgentes para afrontar la emergencia en el ámbito de la vivienda y la pobreza energética. De este paquete de reformas resaltan dos en especial: la nueva definición de gran propietario y la figura del alquiler social obligatorio.

Respecto de los grandes tenedores, la norma indica que tendrán esta consideración las personas jurídicas que sean titulares de más de quince viviendas - la antigua regulación establecía la disposición de más de $1.250 \mathrm{~m}^{2}$ para tener esta consideración-, salvo que se trate de promotores sociales o ya tengan $15 \%$ de la superficie calificada como vivienda de protección oficial. Además, en la definición de gran tenedor también se incluye a las entidades financieras, sus filiales inmobiliarias, los fondos de inversión y las entidades de gestión de activo, junto con las personas físicas que posean más de quince viviendas, siempre con las excepciones previstas también para las personas jurídicas.

El propio Decreto Ley 17/2019 recoge la figura del alquiler social obligatorio. Así, se prevé la obligación de los grandes tenedores de vivienda de formular una propuesta de alquiler social obligatorio y una renovación obligatoria de los contratos de alquiler social que ya existan con una duración mínima que pasa de tres a siete años (cinco años cuando el arrendador es persona física). Por lo tanto, el propietario deberá hacer una oferta de alquiler social en los términos que señalan las normas antes de interponer cualquier tipo de acción judicial por impago, vencimiento de la duración del título jurídico que habilitaba la ocupación o por falta de este título. Por lo tanto, la norma obliga a los grandes propietarios a ofrecer un alquiler social incluso cuando la persona esté ocupando una de sus propiedades sin título jurídico que lo habilite. En este caso, para que concurra la obligación de ofrecer el alquiler social, la vivienda debe haber estado desocupada de forma permanente e injustificada por un plazo de dos años; el ocupante debería haber estado en la vivienda durante, como mínimo, seis meses y no debería haber rechazado ninguna opción de realojamiento social en los últimos dos años.

Por último, en tercer lugar, el Decreto Ley 17/2019 introduce modificaciones en el texto refundido de la Ley de Urbanisno. Entre estas medidas destaca la relativa a la reserva del $30 \%$ del techo para que se califique para uso residencial de nueva implantación, destinados a venta, alquiler o a otras formas de cesión de uso. 
Por otro lado, la Ley 5/2020, del 29 de abril, de medidas fiscales, financieras, administrativas y del sector público y de creación del impuesto sobre las instalaciones que inciden en el medio ambiente, o lo que es lo mismo, la Ley de presupuestos de la Generalitat de Cataluña del año 2020, también ha introducido algunas reformas en materia de vivienda y urbanismo.

En relación con la Ley 18/2007, la Ley de Presupuestos ha introducido algunos cambios en cuanto a los informes de inspección técnica que deberán entregarse junto con los contratos de transmisión de las viviendas. De esta forma, se pretende fomentar el deber de conservación, mantenimiento y rehabilitación de los edificios de viviendas a través de las inspecciones técnicas y sus correspondientes informes.

Por lo que respecta al texto refundido de la Ley de Urbanisno, las modificaciones más destacables son las que se imponen en el régimen jurídico de las licencias urbanísticas que van a requerir del informe de idoneidad técnica para su otorgamiento, con el fin de verificar que el proyecto y la documentación cumplen con la normativa estatal y autonómica que debe ser comprobada. En relación con las reservas de suelo para la construcción de viviendas de protección oficial, la Ley de Presupuestos también indica que el Plan de Ordenación Urbanística Municipal puede prever la destinación total o parcial de la edificación a este tipo de viviendas y que esta medida afecta tanto a edificios de nueva construcción como a aquellos edificios en los que se hayan realizado obras de ampliación, de reforma general o de gran rehabilitación.

En definitiva, previsiones, algunas de ellas más que discutibles desde la técnica jurídica y el derecho de propiedad, para hacer realidad el derecho constitucional a una vivienda digna.

\subsection{La interrelación entre urbanismo y medio ambiente}

El derecho a gozar de un medio ambiente digno, como es sabido, está recogido en el Texto Constitucional (artículo 45). El mismo forma parte, como declaró el Tribunal Europeo de Derechos Humanos en la sentencia López Ostra (9 de diciembre de 1994), del derecho a la inviolabilidad del domicilio (artículo 18 de la Constitución, artículo 8, derecho al respeto a la vida privada en el CEDH) como consecuencia de la inactividad municipal para impedir las molestias producidas por una depuradora instalada sin licencia. Entre las consecuencias que algunos entrevimos de esta sentencia en el ámbito urbanístico, señalaríamos que el plan no puede establecer compatibilidades de usos entre actividades molestas (bares, restaurantes, discotecas) y viviendas, pues este es un límite a la potestad discrecional del planeador, de acuerdo con la actual jurisprudencia del Tribunal Constitucional y la nueva Ley 37/2003, del 17 de noviembre, del ruido. Esa idea del urbanismo ambiental ha sido consagrada a partir de la Ley de Suelo de 2007 (hoy texto refundido de la Ley de Suelo de 2015). 
Dicha interrelación entre derecho urbanístico y medio ambiente también ha sido la filosofía, a nivel comunitario europeo, para solucionar muchos problemas de la utilización racional del territorio y del medio ambiente con el fin de preservar los recursos naturales, paisajísticos, históricos y arqueológicos de generaciones presentes y futuras.

A nivel de derecho europeo, la protección del medio ambiente ha pasado por tres hitos fundamentales. La primera, en que las políticas comunitarias han incidido de manera indirecta en la protección del medio ambiente de los diversos territorios de los Estados miembros. Así ocurría cuando se redactaban normas sobre política agrícola común, transportes, o energía, regulando algunos aspectos de su protección. La segunda fase, que se inicia después del Acta Única Europea, en que el medio ambiente, además, pasa a ser una competencia de la Unión Europea. De esta manera, se dictan normas que inciden directamente en el medio ambiente, como la Directiva de protección y conservación de hábitats naturales y de la flora y la fauna silvestre, la directiva de impacto ambiental que, como sabemos, exige a determinados proyectos concretos la denominada evaluación de impacto ambiental. En la tercera etapa, la actual, la Unión Europea ha decidido proteger el medio ambiente mediante la planificación urbanística de los Estados miembros. Esta decisión, que persigue una uniformización en la protección ambiental, utiliza técnicas mucho más incisivas a nivel europeo.

Con esta idea, los pilares fundamentales en la protección del medio ambiente, a partir de ahora, son los siguientes:

En primer lugar, todas las políticas y acciones comunitarias deben tener en cuenta las exigencias de protección del medio ambiente, con el objeto de garantizar un desarrollo sostenible: es la denominada técnica o principio de integración. A este principio se le ha de añadir el bloque normativo específico que, en materia de derecho ambiental, dicte la Unión Europea, en particular el acervo comunitario compuesto por las directivas europeas y la jurisprudencia del tribunal de justicia.

En segundo lugar, y no obstante lo anterior, se ha comprobado la necesidad de dar un paso más, evitando, por ejemplo, que determinadas industrias o actividades tóxicas, insalubres o nocivas se instalen en otros países de la Unión más permisivos. Por esto, a partir de ahora, las exigencias normativas a nivel europeo referidas a la protección del medio ambiente se tendrán que incorporar a los planes urbanísticos, pasando a protegerse de esta manera el territorio y haciendo realidad, así, el principio de subsidiariedad, pues la aplicación de esta normativa será hecha por las administraciones internas más cercanas al ciudadano, de preferencia por la administración autonómica y la local. Este salto cualitativo que, además, tiende a proteger de manera integral el territorio de la Unión, insisto, mediante las técnicas urbanísticas de cada país, es el que prevé la Directiva 2001/42 del Parlamento Europeo y del Consejo, del 27 de junio, relativa a la evaluación de los efectos de determinados planes y programas sobre el medio ambiente y que, en la actualidad, a nivel estatal, 
ha sido traspuesta por la Ley 21/2013, del 9 de diciembre, adaptada provisionalmente por la disposición adicional octava de la Ley 16/2015 que modifica la Ley catalana 6/2009, del 28 de abril, de evaluación ambiental de planes y programas.

En síntesis, la norma recoge de manera integrada la necesidad de que los planes urbanísticos, la planificación urbanística, recojan estudios previos para analizar los efectos ambientales que su aprobación y ejecución o puesta en práctica puede comportar, con la finalidad de alcanzar la mejor elección y las medidas correctoras pertinentes en cada caso. Es la técnica de la evaluación ambiental estratégica de planes y programas (EAE) con una finalidad claramente preventiva sobre el futuro impacto en el medio ambiente. De ese modo, cuando el planificador urbanístico posee diversas opciones, fruto de la propia discrecionalidad que permite la ley, debe elegir la que menos incidencia tiene en el medio ambiente, contemplando incluso el impacto cero.

Junto a ella, la ley prevé la evaluación de impacto ambiental (EIA), posterior en el tiempo y complementaria de la anterior, que actúa sobre los actos de aplicación concretos de esos planes y programas y, por tanto, va referida a obras, proyectos o instalaciones de gran envergadura, con el propósito de minimizar o suprimir su impacto sobre el medioambiente (la EIA estaba recogida en la Directiva 85/337/CE del Consejo, del 27 de julio de 1985). Aquí la finalidad es preventiva, pero también reparadora.

Como vemos, la evaluación ambiental estratégica es un proceso de evaluación que se incluye en los planes y programas, y es preceptivo y determinante - es decir, para nosotros vinculante-del posterior contenido del plan, contenido que será controlado por el juez de lo contencioso.

\subsection{El control político, social y judicial del urbanismo}

El Estatuto de Autonomía atribuye en su artículo 149 la competencia exclusiva a la comunidad autónoma en la ordenación del territorio y del paisaje, del litoral y el urbanismo. Sobre esta materia, el apartado 5 del citado precepto dice:

Corresponde a la Generalitat, en materia de urbanismo, la competencia exclusiva, que incluye en todo caso:

La regulación del régimen urbanístico del suelo, que incluye en todo caso la determinación de los criterios sobre los diversos tipos de suelo y sus usos. La regulación del régimen urbanístico del suelo, que incluye en todo caso la determinación de los criterios sobre los diversos tipos de suelo y sus usos. 
La regulación del régimen jurídico de la propiedad del suelo, respetando las condiciones básicas que el Estado establece para garantizar la igualdad del ejercicio del derecho de propiedad.

El establecimiento y la regulación de los instrumentos de planeamiento y gestión urbanística, y también de su procedimiento de tramitación y aprobación.

La política del suelo y vivienda, la regulación de los patrimonios de suelo y vivienda y el régimen de la intervención administrativa en la edificación, la urbanización y el uso del suelo y el subsuelo.

La protección de la legalidad urbanística, que incluye, en todo caso, la inspección urbanística, las órdenes de suspensión de obras y licencias, las medidas de restauración de la legalidad física alterada, y también la disciplina urbanística.

Asimismo, recoge el derecho a un medioambiente sostenible y un equilibrio territorial (artículos 46 y 137) y el derecho a la vivienda (artículo 47). Sobre los preceptos que el Estatuto de 2006 dedica a la cuestión, han sido declarados conforme a la Constitución en la sentencia del Tribunal Constitucional del 28 de junio de 2010 los referidos a las distintas competencias autonómicas que afectan, de manera directa o indirecta, al urbanismo, la ordenación del territorio y del paisaje o del litoral (artículo 148 y 149 del Estatuto de Autonomía de Cataluña). De ese modo, y en primer término, es declarado ajustado a la Constitución el informe preceptivo (no vinculante) de la comisión bilateral Generalitat-Estado para la determinación de la ubicación de las infraestructuras y los equipamientos de titularidad estatal en Cataluña (artículo 149.2 del Estatuto). En segundo lugar, es conforme a la Constitución el artículo 149.3.b) del Estatuto que atribuye la competencia a la Generalitat de las funciones ejecutivas de ordenación del litoral (autorizaciones y concesiones), cuyo ejercicio se somete expresamente al régimen general del domino público, que corresponde al Estado.

También, en tercer lugar, es correcto jurídicamente hablando atribuir a la Generalitat la gestión de las obras de interés general cuando estas se sitúen en el litoral catalán (artículo 149.4), precepto que debe ser interpretado en relación con el artículo 148.2 del Estatuto que habilita la participación de la Generalitat en la planificación y programación de las obras de interés general, de conformidad con lo dispuesto en la legislación estatal y el propio Estatuto, respetando el artículo 149.1. 24, 2 CE. Así, por último y en relación con lo anterior, las obras públicas de interés general pueden ser objeto de informe previo de la Generalitat, pues dicho informe afecta a la propia declaración de interés general de esas infraestructuras. 
En consecuencia, la globalidad de preceptos es constitucional.

En cualquier caso, los retos que tiene planteados el urbanismo en Cataluña son, además de los ya apuntados, el de un adecuado control político efectivo tanto por los propios plenos de los ayuntamientos como por la comunidad autónoma en la aprobación definitiva de algunos instrumentos de planeamiento respetando, eso sí, los límites referidos al control de la legalidad estricta y a las determinaciones que afectan a intereses supramunicipales. También se requerirá, a nuestro juicio, una potenciación del control social del urbanismo mediante una adecuada participación ciudadana en el procedimiento de elaboración de planes - y un también adecuado castigo cuando ello no ocurra-, así como la inestimable función que ejercen las asociaciones de vecinos, grupos ecologistas y medios de comunicación.

En tercer lugar, gran parte del éxito o fracaso de la nueva legislación - cargada de buenas intenciones- dependerá de un control judicial real y efectivo. Es necesario que, a falta de más medios, nuestros tribunales de lo contencioso-administrativo, en primer término, utilicen las medidas cautelares que prevé la ley ante posibles desviaciones de la legalidad, evitando que, cuando la sentencia recaiga, esta sea inejecutable. La Ley 29/1998, del 13 de abril, reguladora de la jurisdicción contencioso-administrativa, impone sin vacilaciones esa solución al decir en su artículo 130:

1. Previa valoración circunstanciada de todos los intereses en conflicto, la medida cautelar podrá acordarse únicamente cuando la ejecución del acto o la aplicación de la disposición pudieran hacer perder su finalidad legítima al recurso.

2. La medida cautelar podrá denegarse cuando de esta pudiera seguirse perturbación grave de los intereses generales o de tercero que el juez o tribunal ponderará en forma circunstanciada.

Un uso restrictivo de las medidas cautelares, unido a la duración excesiva de los procesos judiciales, hará fracasar cualquier intento de control judicial del urbanismo. En esa línea, y en segundo lugar, los tribunales deben declararse inflexibles con las deficiencias en la documentación de los planes. Atrás deberían quedar, para siempre, algunas justificaciones que se han hecho cuando faltaba o era incompleto el estudio económico financiero del plan o la memoria justificativa. A esos documentos esenciales la nueva legislación les añade la memoria social, los procedimientos de evaluación ambiental y los informes obligatorios (artículo 86 bis de la Ley de Urbanismo y 115 del reglamento). Ninguno de esos documentos está previsto por el legislador de forma caprichosa y, por tanto, su ausencia o insuficiencia debería ser castigada severamente por la jurisdicción contenciosa. 
En cuarto lugar, es necesario que los tribunales de lo contencioso profundicen en el control judicial de la discrecionalidad urbanística. A los tradicionales límites del respeto a la competencia legalmente establecida, la desviación de poder y el respeto al procedimiento, no puede olvidarse ya el control que deriva de una correcta motivación del contenido del plan, incluida en la memoria, explicando las razones de la elección de la solución prevista entre las distintas posibles, lo que en caso contrario sería una decisión arbitraria, arbitrariedad proscrita por el artículo 9.3 de la Constitución.

Asimismo, el control del núcleo de la discrecionalidad que resulta de los principios de coherencia, racionalidad, proporcionalidad no puede ser ya discutida. En esa línea deben concretarse jurisprudencialmente las consecuencias que se extraen del principio del desarrollo urbanístico sostenible, pasando de la metafísica a la técnica, en palabras del profesor García de Enterría ${ }^{9}$, es decir, dando contenido claro a ese principio.

Por último, el sangrante problema de la inejecución de las sentencias urbanísticas no puede durar ni un día más.

Esas deben ser las líneas fundamentales del control en la aplicación de la legislación urbanística, dejando para la jurisdicción penal las cuestiones más graves tipificadas en los artículos 319 y siguientes del vigente Código Penal. Pero en ningún modo debemos olvidar que el medio natural de control del urbanismo es la jurisdicción contenciosa. Ella es la encargada de restablecer la realidad física alterada, hacer cumplir las normas y ordenar el derribo de lo ilegalmente construido.

\section{CONCLUSIONES}

El derecho urbanístico de Cataluña es el resultado de una larga evolución, un proceso en el que se han afianzado sus competencias exclusivas sobre la materia, de acuerdo con la Constitución española y su Estatuto de Autonomía, que permite que en este territorio la legislación urbanística establezca el modelo de ciudad que se persigue.

A la hora de llevar a cabo esta regulación, no pueden perderse de vista algunos de los principales retos que plantea el derecho urbanístico en Cataluña, la mayoría de los cuales son compartidos con muchos países del continente europeo, como es el caso de Francia o Italia.

En este contexto, destaca la problemática relativa al derecho a la vivienda, la cual no solo tiene implicaciones urbanísticas, sino también de tipo social y medioambiental. Las circunstancias que han llevado a la situación actual son el elevado precio de la vivienda,

9 García de Enterría, "Una reflexión...”. 
el lento cambio en el modelo de usos del suelo y el fenómeno de la inmigración, que han hecho a que, en los últimos años, se adopten medidas extremas urgentes y extremas para solventarlo, y que hacen referencia a la regulación de las denominadas "viviendas vacías", al modelo de vivienda de protección oficial o a la regulación de los precios máximos de los alquileres.

Asimismo, en el trabajo también resaltamos la relevancia de la perspectiva ambiental en la ordenación urbanística, que ha llevado a incorporar elementos de control que tienen por objeto reducir el margen de discrecionalidad del que dispone el planeador, con una finalidad preventiva, pero también reparadora.

Por último, destacamos también la importancia de dotar de nuevas herramientas de control sobre el urbanismo, especialmente respecto del control externo ejercido por el Poder Judicial, para garantizar su efectividad; de esto es especialmente relevante un uso adecuado de las medidas cautelares.

En definitiva, queda aún mucho camino por recorrer y es necesario que los poderes públicos se esfuercen para solucionar todos los problemas señalados, y que lo hagan de tal manera que, protegiendo bienes jurídicos tan relevantes como la vivienda o el medio ambiente, también queden preservados otros valores importantes, como son la seguridad jurídica, evitando, como por desgracia ha sucedido en los últimos años, cambios normativos constantes y erráticos que en nada ayudan a seguir avanzando. 


\section{BIBLIOGRAFÍA}

- Barnes Vázquez, Javier. "La distribución de competencias entre el Estado y las comunidades autónomas en materia de urbanismo: Una síntesis de los criterios fundamentales a la luz de la sentencia del TC 61/97 (I y II)”. La Ley 4.441-4.442 (1997): 1.685-1.696.

- Bassols Coma, Martí. Génesis y evolución del derecho urbanístico wspañol, 1812-1956, Colección de Estudios Jurídicos, monografías núm. 40. Madrid: Montecorvo, 1973.

- Bermejo Vera, José. Derecho administrativo: Parte especial. Navarra: Thomson-Civitas, 1999.

- Carceller Fernández, Antonio. Introducción al derecho urbanístico. Madrid: Tecnos, 1992.

- Cerdà, Ildefons. Teoría de la construcción de las ciudades aplicada al proyecto de reforma del ensanche de Barcelona y Madrid. Barcelona: MAP, Ayuntamiento de Barcelona, 1991.

- Fernández, Tomás Ramón. Manual de derecho urbanístico. 26. ${ }^{a}$ edición. Madrid: Thomson Reuters, 2019.

- García de Enterría, Eduardo. "Una reflexión sobre la supletoriedad del derecho urbanístico español a la vista del siglo XXI”. Revista Española de Derecho Administrativo 95 (1997): 407-416.

- García de Enterría, Eduardo y Luciano Parejo Alfonso. Lecciones de derecho urbanístico. Madrid: Civitas, 1979.

- Gifreu i Font, Judith. L'ordenación urbanística a Catalunya. Madrid: Marcial Pons; Barcelona: ACM, 2012.

- González Pérez, Jesús. Comentarios a la Ley del Suelo. Madrid: Civitas, 1988.

- Lliset Borrell, Francisco. Comentaris a la Llei d'urbanisme de Catalunya. Barcelona: Bayer Hermanos, 2004.

- Lliset Borrell, Francisco, José A. López Pellicer y Federico Romero Hernández. La Ley del Suelo: Comentarios al texto refundido de 1992. Madrid: El Consultor, 1993.

- López Ramón, Fernando. Introducción al derecho urbanístico. Madrid: Marcial Pons, 2013. 
- Menéndez Reixach, Ángel. "Las competencias del Estado y de las comunidades autónomas sobre el régimen del suelo: Comentario crítico a la STC de 20 de marzo de 1997”. Revista de Derecho Urbanístico y Medio Ambiente 31, n. ${ }^{\circ} 153$ (1997): 35-72.

- Pareja Lozano, Carles. El nou Dret urbanístic. Madrid: Marcial Pons, 1998.

- Parejo Alfonso, Luciano y Gerardo Roger Fernández. Comentarios a la Ley de Suelo (Decreto legislativo 2/2008, de 20 de junio). Madrid: Iustel, 2008.

- Quintana López, Tomás (coordinador). Derecho urbanístico estatal y autonómico. Valencia: Tirant lo Blanch, 2001.

- Sánchez Goyanes, Enrique (director). Derecho urbanístico de Cataluña. Madrid: La Ley, 2009.

- Trayter, Joan Manuel (director). Comentarios a la Ley de urbanismo de Cataluña. Pamplona: Thomson-Aranzadi, 2008.

- - Derecho urbanístico de Cataluña. 8. ${ }^{\text {a }}$ edición. Barcelona: Atelier, 2010.

- - "Problemas actuales del derecho urbanístico en el mundo global: El ejemplo de Cataluña”. En Estudios de derecho público en homenaje a Luciano Parejo. Volumen 3. Valencia: Tirant lo Blanch, 2018.

- Trayter, Joan Manuel y Carles García Rocasalva (directores). El desenvolupament de l'autogovern en materia de territorio, paisatge i urbanisme. Barcelona: IEA, 2017. 